\title{
The positive side of psychopathy: Emotional detachment in psychopathy and rational decision-making in the ultimatum game
}

\author{
Takahiro Osumi ${ }^{\mathrm{a}, \mathrm{b}, *}$, Hideki Ohira ${ }^{\mathrm{a}}$ \\ ${ }^{a}$ Department of Psychology, Graduate School of Environmental Studies, Nagoya University, Furo-cho, Chikusa-ku, Nagoya 464-8601, Japan \\ bapan Society for the Promotion of Science (JSPS), Japan
}

\section{A R T I C L E I N F O}

\section{Article history:}

Received 4 January 2010

Received in revised form 20 March 2010

Accepted 21 April 2010

Available online 26 May 2010

\section{Keywords:}

Fairness

Decision-making

Emotion

Electrodermal activity

Psychopathy

\begin{abstract}
A B S T R A C T
An emotional deficit in individuals with psychopathy has been regarded as a potential factor in the disinhibition of selfish behaviors, which can be an impediment to a successful life in human society. However, recent studies in the field of economics have made clear that emotional function is associated with irrational decision-making. In the present study, to test whether psychopathy may have a positive aspect in a social setting, we examined the decision-making of college students with high and low tendencies for psychopathy in the ultimatum game, which illustrates conflict between fairness and economic utility. We also investigated electrodermal responses to fair and unfair offers for each group. Compared to low psychopathic controls, individuals with a high tendency toward psychopathy more often choose economic utility by accepting unfair offers. Whereas controls more often exhibited an electrodermal response to unfair offers compared to fair offers, high psychopathic individuals did not show a similar difference between the types of offer. The results suggest that the affective deficit of psychopathy might be associated with insensitivity to unfairness and may contribute to a rational decision to accept unfair offers. Hence, psychopathy can be rational in some social situations.
\end{abstract}

(c) 2010 Elsevier Ltd. All rights reserved.

\section{Introduction}

Individuals with psychopathy often exhibit antisocial behaviors with no regard for social norms or relationships with other people (Cleckley, 1941). According to an evolutional theory, adherence to social norms or altruistic behaviors would help to build reciprocal relationships with others, which would play a functional role in survival through interpersonal interactions (Trivers, 1971). In contrast, selfish or antisocial behaviors would be an important impediment to adaptive survival in human societies which have established norms or standards to penalize such behaviors. Given the nature of humans and societies, individuals with psychopathy could be considered social misfits.

Nevertheless, the classic description of psychopathy by Cleckley said that psychopathic individuals are not only criminals, but also can be found in any population in society. In line with this, psychopathic traits are found as a sub-clinical continuum in all populations in a society (Edens, Marcus, Lilienfeld, \& Poythress Jr., 2006; Levenson, Kiehl, \& Fitzpatrick, 1995). Furthermore, Lykken (1995) argued that certain characteristics of psychopathy, such as superficial charm, volubility, and fearlessness, are seen in successful busi-

\footnotetext{
* Corresponding author at: Department of Psychology, Graduate School of Environmental Studies, Nagoya University, Furo-cho, Chikusa-ku, Nagoya 4648601, Japan. Tel./fax: +81527892220.

E-mail address: osumi.takahiro@b.mbox.nagoya-u.ac.jp (T. Osumi).
}

nessmen and academics. Thus, psychopathy itself may not be decisive in one's social maladaptation; rather, it may enhance some types of social success. It has been a mystery why psychopathy includes such contradictory aspects as antisocial and successful achievements.

The hallmark of psychopathy is considered to be affective impairment. Subjects with psychopathy fail to exhibit an electrodermal response and show reduced activation of the affective neural circuit in response to aversive stimuli or distress cues from other people (Benning, Patrick, \& Iacono, 2005; Birbaumer et al., 2005; Lorber, 2004; Lykken, 1957). Previous researchers have implied that a reduced experience of emotions accompanied by signals of punishment or distress can result in the disinhibition of socially deviant behaviors (Blair, 1995; Lykken, 1995). Consistent with this notion, recent studies in neuroscience and psychology have noted that emotion plays an important role in inhibiting disadvantageous decision-making (e.g., Bechara \& Damasio, 2005), and several studies have shown that individuals with sub-clinical psychopathic tendencies repeatedly make disadvantageous decisions (e.g., Mitchell, Colledge, Leonard, \& Blair, 2002). However, it is also true that emotional behaviors can result in maladaptive consequences depending on the circumstances or situation (Shiv, Loewenstein, Bechara, Damasio, \& Damasio, 2005; Weller, Levin, Shiv, \& Bechara, 2007). For example, it is conceivable that reactions driven by anger or frustration may cause significant incidents, such as crimes of passion, even if such emotions stem from social 
motivations. If we consider the effects of emotions on social interactions, there may be some circumstances which make it easy for individuals with psychopathy to lead a social life.

The ultimatum game (UG), which is a widely used laboratory model of economic decision-making, illustrates an interpersonal situation in which emotional functions of humans can violate economical rationality. In a game with only one round, two players - a proposer and a responder - have to divide a sum of money. If the responder accepts an offer made by the proposer, the deal goes ahead. However, if the responder rejects it, neither player gets anything. Based on this simple rule, rational responders should accept every positive offer because there will be no additional rounds with the same opponent. However, actual responders often turn down such a rational decision in favor of an irrational rejection: an offer below $20-30 \%$ of the stake has an approximately $50 \%$ chance of being rejected (Güth, Schmittberger, \& Schwarze, 1982). This irrational rejection is considered to be driven by negative emotions such as anger or frustration in response to unfair treatment. As support for this notion, the rate of rejection for unfair offers is positively correlated with activation of the anterior insula (Sanfey, Rilling, Aronson, Nystrom, \& Cohen, 2003), a brain region that is associated with subjective negative emotions (e.g., Critchley, Wiens, Rotshtein, Öhman, \& Dolan, 2004).

In addition, skin conductance response (SCR) following unfair offers has been believed to be a better predictor for irrational rejection in the UG (van't Wout, Kahn, Sanfey, \& Aleman, 2006). Skin conductance activity is a reliable measure to assess physiological arousal mediated by the sympathetic nervous system. Emotional events prompt greater SCRs than neutral events regardless of whether they are pleasant or unpleasant (e.g., Bradley, Codispoti, Cuthbert, \& Lang, 2001). Accordingly, it is presumable that the finding by van't Wout et al. (2006) of SCR associated with rejection for unfair offers derives from negative emotions. However, individuals with psychopathy often exhibit deficient SCR in the aversive conditioning (Lykken, 1957) or during passive viewing of affective pictures, particularly unpleasant pictures (Benning et al., 2005), which suggests that they are less likely to be sensitive to negative emotional events.

Therefore, in the present study we determined whether individuals with high psychopathic tendencies in a non-forensic population rationally accept or irrationally reject unfair offers as a responder in the single-shot UG. Moreover, to investigate emotional responses to offers, we recorded electrodermal activity following an offer as an autonomic index of the emotional state during decision-making. Furthermore, since the average time taken to accept is normally 3-4 s for fair offers and 6-7 s for unfair offers (Knoch, Pascual-Leon, Meyer, Treyer, \& Fehr, 2006), the time that responders are allowed to spend in decision-making might affect their response, despite the individual's preferences. Thus, less time may cause an error and more time may enable a deliberate decision which would override an initial preference. According to the findings by Knoch et al. (2006), $8.0 \mathrm{~s}$ would be enough time to make deliberate decisions for unfair offers. Meanwhile, it might be difficult for responders to override an initial preference if time allotted for making decisions is $3.0 \mathrm{~s}$, or if they have to make decisions more immediately after receiving offers (e.g., $0.5 \mathrm{~s}$ ). However, if psychopathic traits could affect a preference, differences in the acceptance rate between subjects with high and low psychopathic tendencies should be observed whenever they are required to express their decisions. To test this notion we controlled the time that could be spent in decision-making among subjects, and manipulated it by randomly setting the duration of each trial as $0.5 \mathrm{~s}, 3.0 \mathrm{~s}$, or $8.0 \mathrm{~s}$.

The affective impairment of individuals with psychopathy is likely to enhance a rational decision to accept an unfair offer in the UG. If individuals with high psychopathy fail to exhibit nega- tive emotions, they would not show greater SCR in response to unfair offers compared to fair offers. On the other hand, individuals with acquired sociopathy, who exhibit many of the same behaviors as subjects with psychopathy (e.g., Mitchell et al., 2002), due to lesion of the ventromedial prefrontal cortex (VMPFC), have been found to accept unfair offers less often than healthy controls (Koenigs \& Tranel, 2007; Moretti, Dragone, \& di Pellegrino, 2009). Therefore, we could not rule out the possibility that individuals with psychopathy would overreact to unfair offers; i.e., compared to low psychopathic individuals, they may be more likely to irrationally reject unfair offers regardless of whether or not they exhibit SCR in response to these offers.

\section{Methods}

\subsection{Participants}

Twenty-eight participants were recruited from among 128 Japanese college students who consented to participate in the current study, out of 700 who completed the Japanese version of the Primary and Secondary Psychopathy Scales (PSPS: Levenson et al., 1995; Sugiura \& Sato, 2005) during a screening session. The high psychopathic group consisted of 12 students ( 5 females), and the low psychopathic group consisted of 16 students ( 8 females). The mean ages were $19.1(S D=0.49)$ years for the psychopathic group and 19.1 ( $S D=1.27$ ) years for the low psychopathic group. All of the participants were confirmed to have no knowledge of the UG or other economic game theories.

We defined individuals who scored high on primary psychopathy as being psychopathic because the specific properties of psychopathy correspond to primary psychopathy; in contrast, secondary psychopathy has been defined as an aspect of another psychiatric disorder (Karpman, 1948; Lykken, 1995). Thus, we recruited a similar number of male and female participants from extreme ends of students who scored high and low on primary psychopathy. Moreover, based on descriptive statistics of the score for 700 students $(M=34.37, S D=4.58)$, each students scoring over 38.95 and below 34.37 were assigned to the high psychopathic group and the low psychopathic (non-psychopathic) group, respectively. The scores on the primary psychopathy scale were 39-48 $(M=42.17, S D=3.04)$ for the high psychopathic group and 20-34 $(M=30.19, S D=3.92)$ for the low group. A $t$ test showed a significant difference in the mean score of primary psychopathy between the two groups, $t(26)=8.78, p<0.01$. Meanwhile, for secondary psychopathy, the scores were $17-32(M=23.67, S D=5.00)$ for the high group and $17-28(M=22.44, S D=3.86)$ for the low group, and there was no significant difference between the means of the groups, $t(26)=0.74, p=0.47$.

\subsection{Psychopathy assessment}

The PSPS is a 26-item measure designed to detect psychopathic traits in a non-institutionalized population. Each item is a statement that is to be rated on a four-point Likert-type scale (from disagree strongly to agree strongly). The primary psychopathy subscale consists of 16 items related to manipulation, egocentricity and lack of empathy and remorse, whereas the secondary subscale consists of 10 items related to impulsivity, quick-temperedness and poor behavioral control. Consistent with a two-factor model of the Psychopathy Checklist-Revised (PCL-R; Hare, 1991), primary psychopathy, but not secondary psychopathy, was correlated negatively with harm avoidance (Levenson et al., 1995). Furthermore, the PSPS demonstrated adequate reliability and convergent validity with alternative measures of psychopathy (Brinkley, Schmitt, Smith, \& Newman, 2001; Lynam, Whiteside, \& Jones, 1999). A Jap- 
anese version of the PSPS was developed through back translation for the items (Sugiura \& Sato, 2005) and demonstrated the same factor structure, construct validity, and adequate test-retest reliability (Osumi, Kanayama, Sugiura, \& Ohira, 2007). Coefficient alphas in our screening session were .79 for primary psychopathy and .60 for secondary psychopathy, which were approximately equivalent to those in Levenson et al. (1995).

\subsection{Procedure}

The participants played the UG as responders and received 30 offers from 30 different proposers (half of the proposers were female). In each trial, 1000 Japanese yen was divided between two players. Half of the offers were fair ( $¥ 500$ : $¥ 500)$ and the others were unfair (six $¥ 700$ : $¥ 300$; six $¥ 800$ : $¥ 200$; three $¥ 900$ : $¥ 100$ ). In accordance with previous studies (e.g., Koenigs \& Tranel, 2007), the participants were told that the offers had been selected from the results of a survey of other students that had been completed previously and that the proposers' faces had been photographed though the proposers and the offers were actually set by the experimenter. It has been confirmed that this procedure validly evokes subjective emotions (Osumi \& Ohira, 2009). Participants were instructed that they would receive $10 \%$ of the total amount of gain according to their decisions during the 30 trials.

The task began after a three-minute relaxation period. In each trial, a fixation point was initially presented for $5 \mathrm{~s}$. The photograph of the proposer's face was randomly shown for $1 \mathrm{~s}$ and the fixation point was presented again for $7 \mathrm{~s}$. An offer was then presented randomly followed by the response cue. The time interval between an offer and the response cue was also set randomly as $0.5,3.0$, or $8.0 \mathrm{~s}$. When the cue was displayed, participants responded as fast as possible by pressing the left (acceptance) or right (rejection) button with their dominant hand, and feedback was presented for $1 \mathrm{~s}$ (Fig. 1).

\subsection{Skin conductance measurement and analysis}

Electrodermal activity was recorded during the task using an SCL/R unit (DA-2; Vega Systems, Japan) which used a constant $0.5 \mathrm{~V}$. In addition, disposable $\mathrm{Ag} / \mathrm{AgCl}$ electrodes (Vitrode $\mathrm{F}-150$; Nihon Kohden, Japan) filled with gelled isotonic electrolytes were attached to the palmar surface of the index and middle fingers of the nondominant hand. The data, which were stored on a hard disc, were analyzed offline using software (Acknowledge; Biopac Systems, Santa Barbara, CA, USA).
Our purpose of measuring SCR was to investigate sensitivity to offers. However, the task of the present study was not passive viewing, but decision-making for offers, which allowed us to predict that amplitudes of the late SCR during viewing offers would be influenced by internal factors such as conflict, rather than sensitivity to external stimuli. Therefore, because it was necessary to analyze the SCR that was earlier evoked, SCR was defined as the change from the onset to the peak of the response within 0.5-3 s following offer onset in the $3.0 \mathrm{~s}$ and the $8.0 \mathrm{~s}$ conditions. The SCRs in the $0.5 \mathrm{~s}$ condition was excluded from analyses because SCR ordinarily starts after $0.5 \mathrm{~s}$ or later following stimulus onset. A $\log$ transformation $(\log [S C R+1])$ was performed to normalize SCR data (Venables \& Christie, 1980).

\section{Results}

\subsection{Acceptance rate for unfair offers}

To test the group differences in preference for monetary utility rather than fairness in each condition of time allotted for making decisions, we conducted a mixed-model analysis of variance (ANOVA) for the acceptance rate of unfair offers with the two groups of psychopathic tendency (high and low) as a between-subject factor and the three conditions of time allotted for the decision $(0.5,3.0$, and $8.0 \mathrm{~s}$ ) as a within-subject factor. As expected, we found a significant main effect for psychopathic tendencies, $F(1,26)=7.46$, $p<0.01, \eta_{p}^{2}=0.22$, indicating that the high psychopathy group showed a higher acceptance rate for unfair offers $(43.8 \%$ $[S D=16.4 \%])$ than the low group $(25.0 \%$ [SD $=16.4 \%])$. With regard to the time allotted for making decisions, there was no main effect, $F(2,52)=0.81, p=0.45, \eta_{p}^{2}=0.03$, or interaction according to psychopathic tendencies, $F(2,52)=0.07, p=0.93, \eta_{p}^{2}=0.003$ (Table 1 ).

Fig. 2 shows the relation between the individuals' total acceptance rates of unfair offers and scores on the primary psychopathy scale. The Pearson product-moment correlation coefficient supported our hypothesis that the responder was more likely to accept unfair offers as their tendency for psychopathy (primary psychopathy) increased, $r=0.55, p<0.001$. On the other hand, the acceptance rate did not correlate with the tendency for secondary psychopathy, $r=0.15, p=0.22$.

\subsection{Skin conductance}

For SCR, we conducted a two-way repeated measures ANOVA to test the difference between fair and unfair offers in both the high

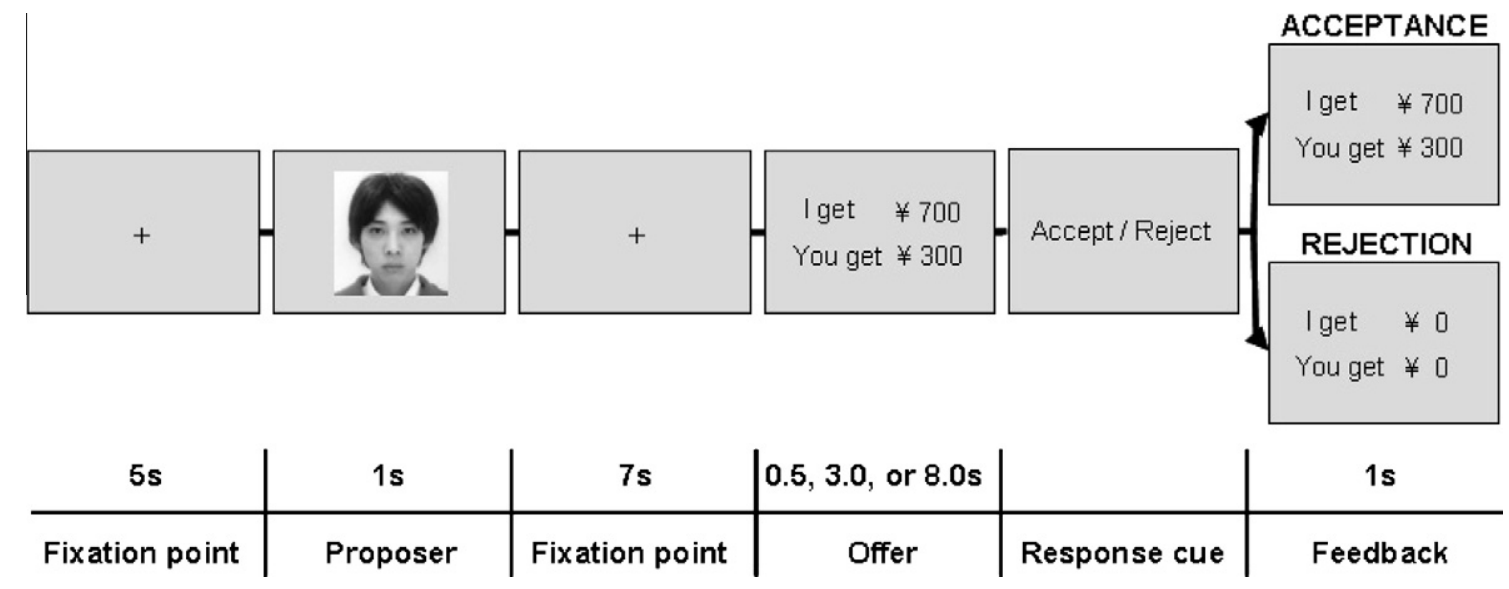

Fig. 1. Time line for a single trial of the ultimatum game. 
Table 1

Mean acceptance rates for unfair offers for each time allotted for making decisions (\%).

\begin{tabular}{llll}
\hline & \multicolumn{4}{l}{ Time allotted for making decisions } \\
\cline { 2 - 4 } & $0.5 \mathrm{~s}$ & $3.0 \mathrm{~s}$ & $8.0 \mathrm{~s}$ \\
\hline Psychopathic & $40.0(23.1)$ & $45.0(18.5)$ & $43.3(21.3)$ \\
Non-psychopathic & $21.2(18.0)$ & $26.2(24.2)$ & $27.5(19.8)$ \\
\hline
\end{tabular}

Note: Standard deviations are in parentheses.

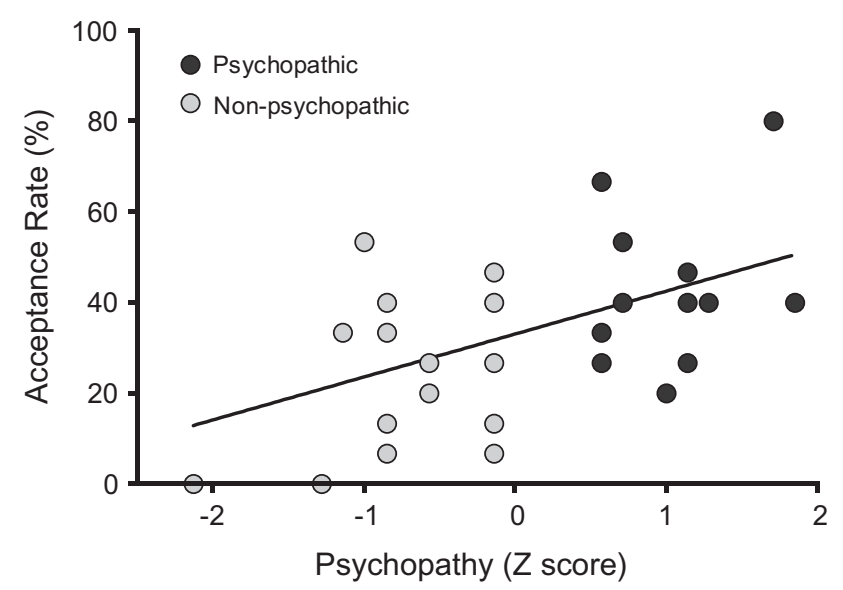

Fig. 2. Scatter plot depicting the correlation between the score of psychopathy and the acceptance rate for unfair offers. The dark and light points indicate the psychopathic and non-psychopathic groups, respectively.

and low psychopathic groups. The analysis revealed a significant interaction between fairness and group, $F(1,26)=3.68, p=0.07$, $\eta_{p}^{2}=0.12$, indicating that while the low psychopathic group showed a greater SCR in response to unfair offers compared to fair offers, $t(15)=-2.62, p=0.02$, the high psychopathic group did not, $t(11)=0.16, p=0.88$ (Fig. 3). A correlational analysis also supported the relationship between psychopathic tendency and emotional hypo-arousal: the Pearson coefficient indicated that the psychopathic tendency was negatively correlated with the difference in the SCR in response to unfair vs. fair offers, $r=-0.29$, $p=0.07$ (one-tailed).

Moreover, we tested the correlation between the acceptance rate and the difference in the SCR in response to unfair vs. fair

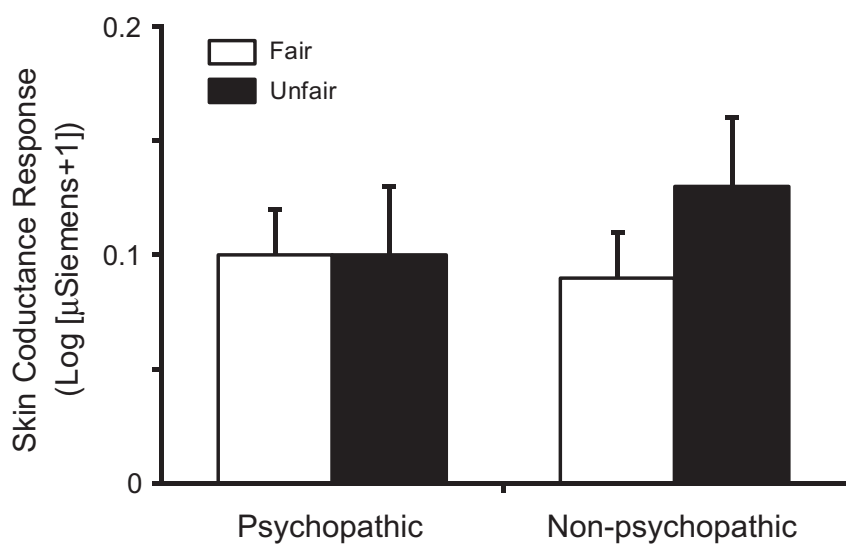

Fig. 3. Mean standardized values of the skin conductance response associated with fair (white bar) and unfair offers (black bar) in the psychopathic and nonpsychopathic groups. Error bars show standard errors. offers. An analysis of Pearson's correlation coefficient revealed a significant relation: participants who accepted fewer unfair offers exhibited a greater SCR in response to unfair offers compared to fair offers, $r=-0.37, p=0.03$ (one-tailed).

\section{Discussion}

In the single-shot UG, individuals with a high tendency toward psychopathy more often accepted unfair offers than those with a low tendency. This behavioral pattern was observed regardless of whether the subjects were required to express their decisions immediately or late. Although random assignment of time intervals during the trials might influence the decision-making process of participants, it was sure that in the $3.0 \mathrm{~s}$ and the $8.0 \mathrm{~s}$ conditions, participants had longer intervals to change strategies after the offers were presented. Despite this, their acceptance rates were not different among these conditions. Additionally, since the score of secondary psychopathy representing impulsivity was equal in both groups and not correlated with acceptance rate, it is difficult to explain the higher acceptance rate in high psychopathic individuals as a consequence of impulsivity. Therefore, the present findings suggest that their decisions represent their preferences as affected by psychopathic traits, and are neither errors arising from immediate decision-making nor the results of deliberation.

While individuals with a low tendency toward psychopathy showed a greater SCR in response to unfair vs. fair offers as a default, high psychopathic individuals showed equal amplitudes of SCR in response to both fair and unfair offers. SCR is often modulated by emotional arousal (Bradley et al., 2001). In addition, a lower SCR was associated with a higher acceptance rate, which may support an emotional reason for irrational rejection (Sanfey et al., 2003; van't Wout et al., 2006) Therefore, although we did not measure subjective ratings for emotions or subjective fairness, the present results of an autonomic index allow us to suggest more objectively and strongly that individuals with psychopathy are insensitive to violation of a fairness norm. This interpretation is consistent with the previous notion that the core of psychopathy is affective dysfunction. Specifically, dysfunction of the amygdala has been considered to play a central role in the emergence of psychopathy (Blair, 2006). Consistent with this position, a previous study reported that psychopathic traits were related to reduced activation of the amygdala during a moral judgment task (Glenn, Raine, \& Schug, 2009). While there have been no empirical findings regarding the activation and deactivation of the amygdala during decision-making in the UG, activation of the amygdala, which is positively correlated with subjective arousal, predicts an individual's determination of magnitudes of punishment for criminal scenarios (Buckholtz et al., 2008). Those findings permit us to speculate that poor affective processing related to the amygdala as a function of psychopathy may reduce the sensitivity to a violation of a fairness norm and/or may make responders lose interest in rejecting unfair offers.

Although the VMPFC has also been considered to be one of the neural bases of psychopathy (Blair, 2006), the rational acceptance of unfair offers by individuals with psychopathy is evidently inconsistent with previous findings in patients with lesion of the VMPFC (Koenigs \& Tranel, 2007; Moretti et al., 2009). In the previous studies, individuals with psychopathy have shown behavioral patterns similar to those of VMPFC patients in economic decision-making (e.g., Mitchell et al., 2002) and reduced activation of the VMPFC during emotional tasks with either a social or non-social domain (e.g., Birbaumer et al., 2005; Rilling et al., 2007). Despite these findings, psychopathy does not seem to be associated with a deficit in reward processing, which has been suggested to be a functional role of the VMPFC, specifically for responders in the UG (Moretti 
et al., 2009; Tabibnia, Satpute, \& Lieberman, 2008), since intact positive emotions have been reported for psychopathy (e.g., Benning et al., 2005). Some characteristics of psychopathic traits, which are not related to the function of the VMPFC, might positively affect the rational behavioral pattern. Machiavellianism, for example, roughly, but not fully, overlaps the concept of psychopathy (McHoskey, Worzel, \& Szyarto, 1998; Paulhus \& Williams, 2002), and Machiavellian people are likely to show the same strategic decision-making in the single-shot UG as individuals with psychopathy (Meyer, 1992). However, further studies are required to understand the uniqueness of psychopathy because Machiavellian people differ from psychopaths in that some cases show social preferences and emotional responding (Spitzer, Fischbacher, Herrnberger, Grön, \& Fehr, 2007).

The rejection of unfair offers has been considered to be a punishment for norm violators (Fehr \& Gachter, 2002) or inequity aversion (Page \& Nowak, 2000). According to these theories, responders expect to gain more profits in long-term future interactions if they pay the present cost for the punishment or inequity aversion. On the other hand, if responders do not so, they will fail to correct the opponent's behavior and damage their reputation, which may increase the risk of repeating this unfair treatment. As can be seen in the present study, however, psychopathic individuals less often accept the costs of the rejection of unfair offers, which could be interpreted as indicating that they ignore long-term reciprocal strategies in interpersonal interactions. A similar behavioral tendency has been reported by a study using the Prisoner's Dilemma. Thus, despite the risk of a breakdown in a cooperative relationship with a partner, psychopathic men were more likely to defect for a short-term gain by taking a free ride on the partner's cost for cooperation (Rilling et al., 2007). Given this seeming fixation for shortterm benefits, psychopathy may still be considered as nothing more than a maladaptive concept in our social life.

Nevertheless, in the single-shot UG, a responder has no further chances to interact with the same proposer. Thus, paying a cost for the rejection of unfair treatment can be regarded as vengeance for nothing since there is no way that the responder will receive reciprocal gains, either directly or indirectly. In this sense, the singleshot UG can be considered a situation in which the regulation of an emotional reaction is required for adaptive decision-making in a social interaction. Therefore, the acceptance of any offer could be defined as success since this is the only method to maximize gains within the 'ultimatum' bargaining. From this perspective, we demonstrated that individuals with psychopathy selected the rational solution in social exchanges with others. This finding supports the previous implication that there are some cases in which individuals with psychopathy show successful aspects (Cleckley, 1941; Lykken, 1995). Accordingly, we conclude that affective impairment of psychopathy is not necessarily maladaptive, but can be linked to adaptive outcomes in society.

\section{Acknowledgment}

This study was supported by a Grant-in-Aid for JSPS Fellows (No. 205962) and a Grant-in-Aid for Exploratory Research (No. 19653075) from JSPS.

\section{References}

Bechara, A., \& Damasio, A. R. (2005). The somatic marker hypothesis: A neural theory of economic decision. Games and Economic Behavior, 52, 336-372.

Benning, S. D., Patrick, C. J., \& Iacono, W. G. (2005). Psychopathy, startle blink modulation, and electrodermal reactivity in twin men. Psychophysiology, 42, 753-762.

Birbaumer, N., Veit, R., Lotze, M., Erb, M., Hermann, C., Grodd, W., et al. (2005). Deficient fear conditioning in psychopathy. Archives of General Psychiatry, 62, 799-805.
Blair, R. J. R. (1995). A cognitive developmental approach to morality: Investigating the psychopath. Cognition, 57, 1-29.

Blair, R. J. R. (2006). The emergence of psychopathy: Implications for the neuropsychological approach to developmental disorders. Cognition, 101, 414-442.

Bradley, M. M., Codispoti, M., Cuthbert, B. N., \& Lang, P. J. (2001). Emotion and motivation I: Defensive and appetitive reactions in picture processing. Emotion, 1, 276-298.

Brinkley, C. A., Schmitt, W. A., Smith, S. S., \& Newman, J. P. (2001). Construct validation of a self-report psychopathy scale: Does Levenson's self-report psychopathy scale measure the same construct as Hare's psychopathy checklist-revised? Personality and Individual Differences, 31, 1021-1038.

Buckholtz, J. W., Asplund, C. L., Dux, P. E., Zald, D. H., Gore, J. C., Jones, O. D., et al. (2008). The neural correlates of third-party punishment. Neuron, 60, 930-940.

Cleckley, H. (1941). The mask of sanity. St. Louis, MO: Mosby.

Critchley, H. D., Wiens, S., Rotshtein, P., Öhman, A., \& Dolan, R. (2004). Neural systems supporting interoceptive awareness. Nature Neuroscience, 7, 189-195.

Edens, J. F., Marcus, D. K., Lilienfeld, S. O., \& Poythress, N. G. Jr., (2006). Psychopathic, not psychopath: Taxometric evidence for the dimensional structure of psychopathy. Journal of Abnormal Psychology, 115, 131-144.

Fehr, E., \& Gachter, S. (2002). Altruistic punishment in humans. Nature, 415, 137-140.

Glenn, A. L., Raine, A., \& Schug, R. A. (2009). The neural correlates of moral decisionmaking in psychopathy. Molecular Psychiatry, 14, 5-6.

Güth, W., Schmittberger, R., \& Schwarze, B. (1982). An experimental analysis of ultimatum bargaining. Journal of Economic Behavior \& Organization, 3, 367-388.

Hare, R. D. (1991). The Hare psychopathy checklist-revised. Toronto: Multi-Health Systems.

Karpman, B. (1948). The myth of psychopathic personality. American Journal of Psychiatry, 103, 523-534.

Knoch, D., Pascual-Leon, A., Meyer, K., Treyer, V., \& Fehr, E. (2006). Diminishing reciprocal fairness by disrupting the right prefrontal cortex. Science, 314, 829-832.

Koenigs, M., \& Tranel, D. (2007). Irrational economic decision-making after ventromedial prefrontal damage: Evidence from ultimatum game. The Journal of Neuroscience, 27, 951-956.

Levenson, M. R., Kiehl, K. A., \& Fitzpatrick, C. M. (1995). Assessing psychopathic attributes in non-institutionalized population. Journal of Personality and Social Psychology, 68, 151-158.

Lorber, M. F. (2004). Psychophysiology of aggression, psychopathy, and conduct problems: A meta-analysis. Psychological Bulletin, 130, 531-552.

Lykken, D. T. (1957). A study of anxiety in the sociopathic personality. Journal of Abnormal and Social Psychology, 55, 6-10.

Lykken, D. T. (1995). The antisocial personalities. Hillsdale, NJ: Lawrence Erlbaum.

Lynam, D., Whiteside, S., \& Jones, S. (1999). Self-reported psychopathy: A validation study. Journal of Personality Assessment, 73, 110-132.

McHoskey, J. W., Worzel, W., \& Szyarto, C. (1998). Machiavellianism and psychopathy. Journal of Personality and Social Psychology, 74, 192-210.

Meyer, H. (1992). Norms and self-interest in ultimatum bargaining: The prince's prudence. Journal of Economic Psychology, 13, 125-132.

Mitchell, D. G. V., Colledge, E., Leonard, A., \& Blair, R. J. R. (2002). Risky decisions and response reversal: Is there evidence of orbitofrontal cortex dysfunction in psychopathic individuals? Neuropsychologia, 40, 2013-2022.

Moretti, L., Dragone, D., \& di Pellegrino, G. (2009). Reward and social valuation deficits following ventromedial prefrontal damage. Journal of Cognitive Neuroscience, 21, 128-140.

Osumi, T., Kanayama, N., Sugiura, Y., \& Ohira, H. (2007). Validation of the Japanese version of the primary and secondary psychopathy scales. The Japanese Journal of Personality, 16, 117-120.

Osumi, T., \& Ohira, H. (2009). Cardiac responses predict decisions: An investigation of the relation between orienting response and decisions in the ultimatum game. International Journal of Psychophysiology, 74, 74-79.

Page, K. M., \& Nowak, M. A. (2000). A generalized adaptive dynamics framework can describe the evolutionary ultimatum game. Journal of Theoretical Biology, 209, 173-179.

Paulhus, D. L., \& Williams, K. M. (2002). The dark triad of personality: Narcissism, Machiavellianism, and psychopathy. Journal of Research in Personality, 36, 556-563.

Rilling, J. K., Glenn, A. L., Jairam, M. R., Pagnoni, G., Goldsmith, D. R., Elfenbein, H. A., et al. (2007). Neural correlates of social cooperation and non-cooperation as a function of psychopathy. Biological Psychiatry, 61, 1260-1271.

Sanfey, A. G., Rilling, J. K., Aronson, J. A., Nystrom, L. E., \& Cohen, J. D. (2003). The neural basis of economic decision-making in the ultimatum game. Science, 300 , 1755-1758.

Shiv, B., Loewenstein, G., Bechara, A., Damasio, H., \& Damasio, A. R. (2005). Investment behavior and the negative side of emotion. Psychological Science, 16, 435-439.

Spitzer, M., Fischbacher, U., Herrnberger, B., Grön, G., \& Fehr, E. (2007). The neural signature of social norm compliance. Neuron, 56, 185-196.

Sugiura, Y., \& Sato, A. (2005). Validation of the Japanese version of primary and secondary psychopathy scale. In: Poster session presented at the 69th meeting of the Japanese Psychological Association, Tokyo, Japan.

Tabibnia, G., Satpute, A. B., \& Lieberman, M. D. (2008). The sunny side of fairness: Preference for fairness activates reward circuitry (and disregarding unfairness activates self-control circuitry). Psychological Science, 19, 339-347. 
Trivers, R. L. (1971). The evolution of reciprocal altruism. The Quarterly Review of Biology, 46, 35-57.

van't Wout, M., Kahn, R. S., Sanfey, A. G., \& Aleman, A. (2006). Affective state and decision-making in the ultimatum game. Experimental Brain Research, 169, 564-568.
Venables, P. H., \& Christie, M. J. (1980). Electrodermal activity. In I. Martin \& P. H. Venables (Eds.), Techniques in psychophysiology (pp. 3-67). Chichester: Wiley. Weller, J. A., Levin, I. P., Shiv, B., \& Bechara, A. (2007). Neural correlates of adaptive decision making for risky gains and losses. Psychological Science, 18 958-964. 